
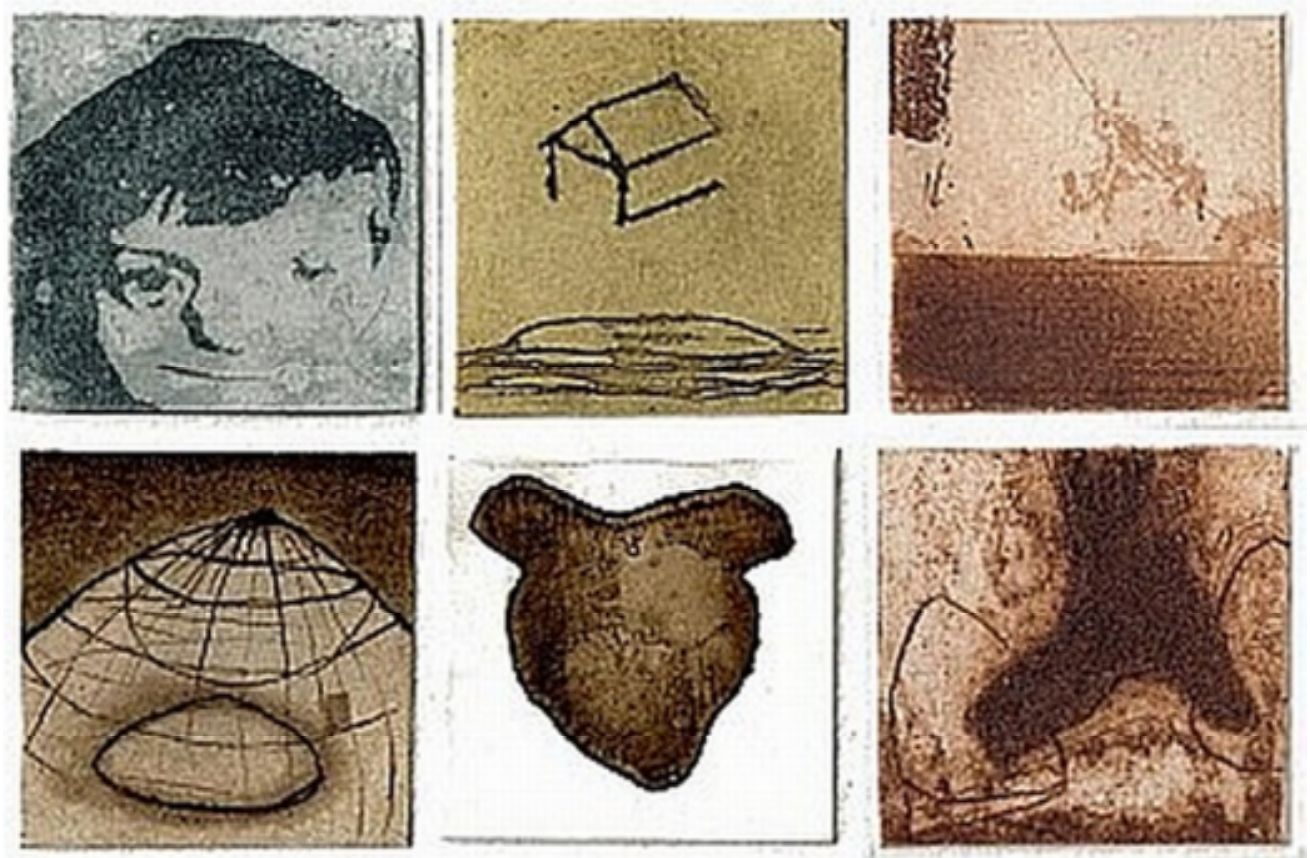

Ilustrações Igor Godinho

\title{
Exercícios a partir de graforismos
}

O número 3 da revista txt inaugura uma nova seção, imagEnta (imagem+ementa), para provocar o debate de seus leitores sobre algumas questões tais como:

Toda leitura de imagem provoca a produção de um texto?

Quantos textos poderíamos ler numa mesma imagem?

Toda imagem está sujeita a alguma tradução, tornando-se um texto?

Poderíamos formular essas questões em relação a textos?

Os Graforismos de Igor Godinho deixam-nos ler seu texto?

Nas aulas do curso Teorias de rede e ensino de literatura, da Graduação em Letras/UFMG, os alunos criaram as seguintes construções aforísticas, as quais revelam sua leitura das imagens produzidas por Igor Godinho. 


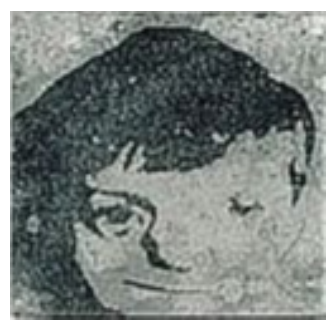

Um olhar nunca é tão enigmático quanto atrás de uma máscara intemporal. Camila Menezes - $7^{\circ}$. período Letras/UFMG

Viver é entender que sempre se estará incompleto...

Michele Ferreira da Silva - 5 o. período Letras/UFMG

O que os olhos vêem é apenas uma parte deformada por eles.

Vemos o que esperamos quando não temos outros olhos para ver no nosso lugar.

Monstros surgem do que não está claro e o que está claro esconde monstros para quem quer procurar.

As imagens aparecem em formas/fôrmas repetidas de seres diferentes. Elberson Justino de Medeiros - $6^{\circ}$. período Letras/UFMG

A diferença desperta a sensibilidade e induz a transformação. Kele Ferreira Martins - $7^{\circ}$. período Letras/UFMG

Nem mesmo nossos dois olhos conseguem ser iguais. A face deforma-se a cada dia. Glauciene Lara



O fluxo do tempo é implacável diante de tudo aquilo que é vida. Michele Ferreira da Silva - 5 o. período Letras/UFMG

Cada pequena parte do mundo consegue representá-lo em sua integridade. Kele Ferreira Martins - $7^{\circ}$. período Letras/UFMG

O pulmão faz a densa troca com o mundo.

Conhecer é uma viagem ao redor do mundo. Não se encontra a totalidade ou a essência.

Conhecer é estar no fluxo.

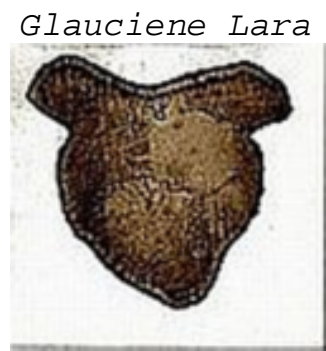

O que para uns parece uma pedra, para outros pode ser um coração. Kele Ferreira Martins - $7^{\circ}$. período Letras/UFMG

O coração é uma terra estranha, um terreno baldio, uma fruta maciça. Glauciene Lara 


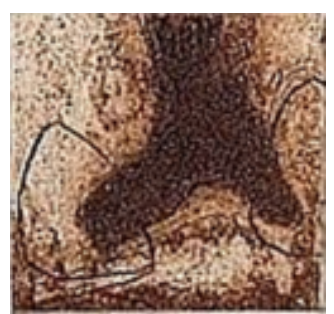

A imaginação faz um borrão de tinta parecer o que a gente quiser. Kele Ferreira Martins - $7^{\circ}$. período Letras/UFMG

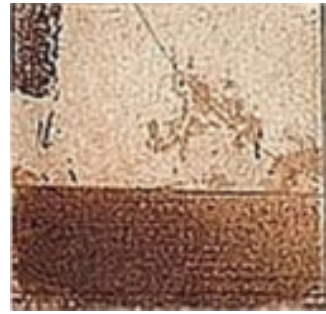

A linha do horizonte é apenas o limite da visão humana.

o sonho e o caos mostram melhor a realidade do que a linearidade a que estamos acostumados. Kele Ferreira Martins - $7^{\circ}$. período Letras/UFMG

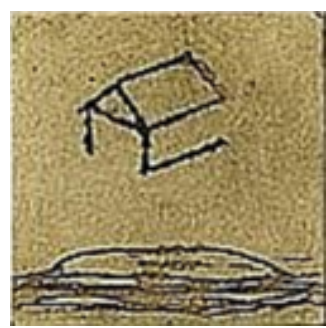

A distância deixa ver as arestas mas não mostra a casa inteira. Glauciene Lara

Aforismos

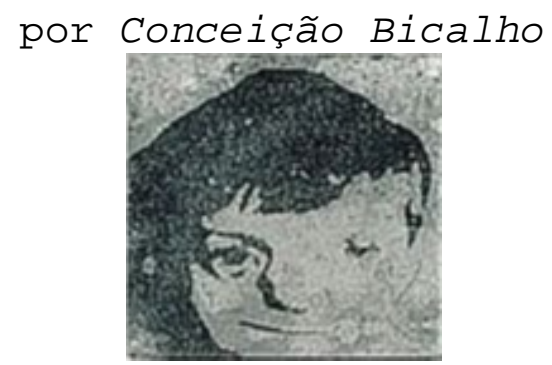

Meio a meio a face assimétrica, dual tessitura do estranho e sem conflito.

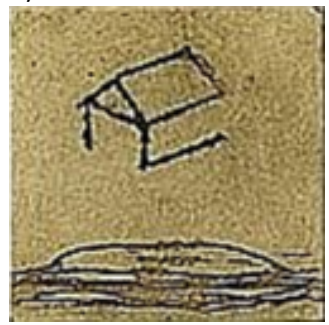

LA 2A, constructo de signos compactados, levita em sonhos sobre a paisagem. 


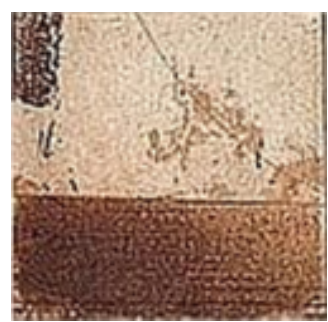

A linha por um triz se esgarça em sombra sobre o espelho de um rio.

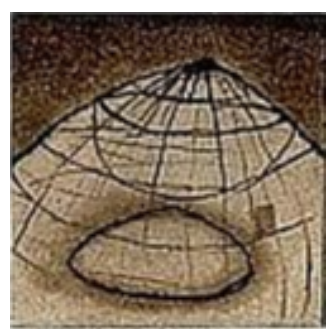

Mundo, re-presentação, curva demarcada assegura o mais elevado sobre o vazio seio da gravidade.

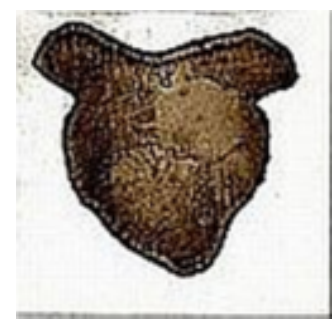

Cora, Couraça, máscara de sentir o sem sentido.

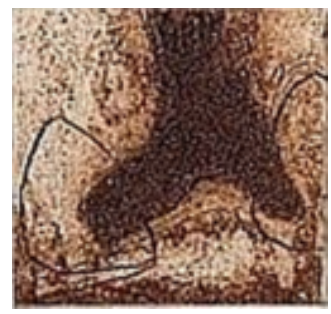

OSfiletes perturbados na superfície obscuramente iluminadaSO 